\title{
A comparative study of energetics of ferrocenium and ferrocene
}

\author{
Shawkat Islam and Feng Wang* \\ Molecular Model Discovery Laboratory, Department of Chemistry and Biotechnology, Faculty \\ of Science, Engineering and Technology, Swinburne University of Technology, Hawthorn, \\ Melbourne, Victoria, 3122, Australia. \\ E-mail: fwang@swin.edu.au (F. Wang)
}

\begin{abstract}
Ferrocenium $\left(\mathrm{Fc}^{+}\right)$inherits a number of molecular/electronic properties from the neutral counterparts' ferrocene $(\mathrm{Fc})$ including the high symmetry. Both $\mathrm{Fc}^{+}$and $\mathrm{Fc}$ prefer the eclipsed structure $\left(D_{5 h}\right)$ over the staggered structure $\left(D_{5 \mathrm{~d}}\right)$ by an energy of $0.36 \mathrm{kcal} \cdot \mathrm{mol}^{-1}$. The present study using the recently developed excess orbital energy spectrum (EOES) shows that the open shell $\mathrm{Fc}^{+}$cation exhibits similar conformer dependent configurational changes to the neutral Fc conformer pair. A further energy decomposition analysis (EDA) discloses that the reasons for the preferred structures are different between $\mathrm{Fc}^{+}$and $\mathrm{Fc}$. The dominant differentiating energy between the $\mathrm{Fc}^{+}$conformers is the electrostatic energy $\left(\Delta \mathrm{E}_{\mathrm{Estat}}\right)$, whereas in neutral $\mathrm{Fc}$, it is the quantum mechanical Pauli repulsive energy $\left(\Delta \mathrm{E}_{\text {Pauli }}\right)$. Within the $\mathrm{D}_{5 \mathrm{~h}}$ conformer of $\mathrm{FC}^{+}$, the EOES reveals that the $\alpha$-electrons of $\mathrm{Fc}^{+}$experience more substantial conformer dependent energy changes than the $\beta$-electrons (assumed the hole is in a $\beta$ orbital).
\end{abstract}

Keywords: Ferrocenium conformers, electron structure of organometallic complexes, excess orbital energy spectrum (EOES), $\alpha$ - and $\beta$-electrons of $\mathrm{Fc}^{+}$, energy decomposition analysis (EDA).

\section{Introduction}

Ferrocene is one of the most studied milestone molecules in chemistry but it has been an excellent example of "wrong but seminal" in history. ${ }^{1}$ The ground electronic state $\left(\mathrm{S}_{1}\right)$ structure of ferrocene $(\mathrm{Fc})$ is surprisingly difficult to resolve unambiguously in both theory and experiment $^{2-6}$ because the orientation of two parallel cyclopentadienyl $(C p)$ rings results in eclipsed $(E)$ or staggered $(S)$ conformers with very small differences in energies and other properties. The pair of important conformers of $F c$, i.e., the eclipsed $(E) F c$ with the $D_{5 h}$ point symmetry and the staggered (S) Fc with the $D_{5 d}$ point symmetry, brings a significant challenge to organometallic chemistry for over half a century. Due to the similarities of the Fc conformers, 
it is critically important to identify at least one particular property of Fc which can differentiate between the $\mathrm{E}$ and $\mathrm{S}$ conformers of Fc. Unfortunately, no study has been able to obtain such conclusive properties until a recent theory led study of Fc using infrared (IR) spectroscopy. ${ }^{5}$ Despite significant advances in experimental techniques such as XAFS which has been employed to study $\mathrm{Fc},{ }^{7}$ and the first comprehensive study of Fc dynamics based on theory and a series of theory-guided infrared (IR) spectral measurements, ${ }^{8}$ it concluded that the FC is in eclipsed form at low temperature (e.g. $0 \mathrm{~K}$ ) and becomes a mixture of both conformers at higher temperatures such as room temperature $300 \mathrm{~K}^{7,9}$

Ferrocene has been studied extensively in the literature. It is found that many methods such as $(\mathrm{u}) \mathrm{HF}$ and $(\mathrm{u}) \mathrm{MP} 2$ with a variety of basis sets were unable to describe transition metalcontaining complexes like Fc appropriately. ${ }^{10}$ It is known that the HF method overestimates the metal-ligand bond due to neglecting the electron correlation energy. ${ }^{11,}{ }^{12}$ While the MP2 method underestimates such the metal-ligand bond due to inappropriate electron correlation. ${ }^{10,13}$ In addition, the results produced by the "gold-standard" ${ }^{14} \operatorname{CCSD}(\mathrm{T})$ method agree well with measured bond lengths etc., but other properties such as IR spectroscopic data do not bring equally excellent agreement to measurements. Coriani et al., ${ }^{10}$ and our previous studies $^{3,5}$ indicated that the B3LYP model, when combined with appropriate basis set, yielded the best results for ferrocene conformers. Other possible contributing factors such as relativistic effects and long-range dispersion forces etc ${ }^{15-19}$ may also exist, but they wouldn't play significant roles in Fc conformer studies due to cancellations. ${ }^{3,20,21}$ It has been confirmed by Salzner, ${ }^{22}$ that the application of relativistic pseudo-potentials doesn't apparently change the results. ${ }^{23,24}$ As a result, B3LYP and unrestricted B3LYP (UB3LYP) theory together with the $\mathrm{m} 6-31 \mathrm{G}(\mathrm{d})$ basic set ${ }^{25}$ has been proven to be one of the most appropriate combinations, is employed in the present study for $\mathrm{Fc}^{+}$.

Structure and properties of the staggered (S) and eclipsed (E) conformers of neutral Fc are markedly similar. Our recent DFT study ${ }^{5}$ accurately predicted that the Fc conformer signature vibrational transitions lie in the region of $400-500 \mathrm{~cm}^{-1}$ of the IR spectra, which is so far the best property to identify E/S conformer of Fc, as almost all other properties of the Fc conformers are either identical or almost impossible to measure. ${ }^{5}$ Such the discovery of FC conformers stimulates a number of significant experimental and theoretical studies. ${ }^{3,}$, , 9, 20, 26 For example, a recent highly accurate X-ray absorption fine structures (XAFS) study of ferrocene $(F c)$ confirmed a near-eclipsed $D_{5 h}$ geometry at low-temperature, ${ }^{7,} 9$ in agreement with our earlier theoretical results. ${ }^{5}$ The recent self-consistent temperature and environment sensitive IR spectral study of Fc, by a series of Synchrotron-based high-resolution IR spectral measurements provided insight on the electronic structure changes of Fc with temperature. ${ }^{8}$ 
In order to understand why the electronic structure of Fc changes with respect to $E$ and $S$ conformer, we recently introduced a molecular orbital theory based excess orbital energy spectrum (EOES) to study ferrocene conformers (E-Fc and S-Fc) with great details. ${ }^{3}$ The EOES takes the orbital energy differences $\left(\Delta \varepsilon_{i}\right)$ between the corresponding orbitals of a conformer pair concerned. ${ }^{3}$ Applying the EOES to all electrons of E-Fc against the corresponding electrons of $\mathrm{S}-\mathrm{Fc}$, we discovered that the transition metal $\mathrm{Fe}$ dominant/associated orbitals experience the most significant change between the conformers in addition to only two pairs of orbitals originated from the cyclopentadienyl ligand. It is the EOES which reveals that the chemical bonding of ferrocene conformers is deeply rooted in the core. ${ }^{3}$ Based on the information from EOES, the exclusive orbitals of Fc conformational changes can be identified. ${ }^{3}$

Ferrocenium inherits many properties including conformation and high symmetry from the parent neutral ferrocene. Ferrocenium cation $\left(\mathrm{Fc}^{+}\right)$is produced when an electron (say, a $\beta$ electron) is removed from the neutral ferrocene (Fc) during the ionization process. The cation, $\mathrm{Fc}^{+}$is unable to be measured in isolation, which makes theoretical studies the ultimate option for $\mathrm{Fc}^{+}$studies in isolation. Similar to the $\mathrm{Fc}$, the cation $\mathrm{Fc}^{+}$also exists as $\mathrm{E}$ and $\mathrm{S}$ conformer. As a result, some questions are yet to be answered such as, how different the electrons and/or their energetic properties in ferrocene and ferrocenium? Would the ionization of neutral ferrocene only impact on the outer valence electrons of $\mathrm{Fc}^{+}$? That is, in addition to the changes in the outer valence electrons upon ionization, what are the change to other electrons such as core electrons? How differently the $\alpha$ - and $\beta$-electrons respond to the removal of a ( $\beta$-)electron from ferrocene? The art of theoretical studies is that the molecule systems can be studied under conditions that are not possible or too difficult in practice for particular insight, such as the study of ferrocenium cation alone and how the energy components change due to such ionization, etc. The present study aims to investigate how differently the electrons (and their energetics) behave in the conformers of neutral $\mathrm{Fc}_{\mathrm{n}}$ and $\mathrm{Fc}^{+}$, and the behavior of the $\alpha$ - and $\beta$ electrons between $\mathrm{E}-\mathrm{Fc}^{+}$and $\mathrm{S}-\mathrm{Fc}^{+}$upon ionization, with minimum environmental interactions.

\section{Computational Section}

The ferrocenium structure is optimized using quantum mechanical methods, both ab initio and density functional theory (DFT) methods. For example, the methods include unrestricted Hartree-Fock (uHF), unrestricted second-order Møller-Plesset perturbation theory (UMP2), hybrid DFT functional based unrestricted (u)B3LYP and restricted open-shell B3LYP (ROB3LYP) levels of theory. Followed by optimization, the infrared spectra were calculated, 
which agrees well with recently measured FT-IR spectra and calculations. More recently developed functionals such as CAM-B3LYP and meta-hybrid functional M06-2X ${ }^{27}$ are also examined for Fc. However, among the quantum mechanical methods mentioned above, the B3LYP functional was found to produce the binding energy more efficiently than a number of DFT functionals including PBE0 and M06 etc. ${ }^{15}$ In addition, the B3LYP functional is known to be able to produce the accurate shape of molecular (Dyson) orbitals. ${ }^{28,} 29$

The basis set used in this study is the $m 6-31 G(d) .{ }^{25}$ This particular basic set employs the standard $6-31 G(d)$ for all atoms except the transition metal Fe which uses m6-31G(d). It describes the atomic $3 d^{7} 4 s^{1}$ and $3 d^{6} 4 s^{2}$ configurations for the central metal Fe atom in Fc by modifying the d-shell functions of Fe. ${ }^{25}, 30$ The original 6-31G(d) basis set for Fe lacked a moderately diffuse outer exponent, which is required to obtain reliable molecular properties for the complex. ${ }^{25}$ In addition, the $\mathrm{m6-31G(d)}$ basis set can reproduce the relative energies of the most important configurations in all first-row transition metal atoms and their singly charged cations, which is a prerequisite of good performance for these molecules. ${ }^{25}$ In our previous study, the B3LYP/m6-31G(d) model was found not only to produce the most accurate infrared (IR) spectra of Fc without any scaling, ${ }^{5}$ but also to differentiate the striking similarities between the Fc conformers. ${ }^{3}$

The orbital irreducible representations and their respective compositions of both conformers are on one-to-one correspondence in $\mathrm{Fc}^{+}$. As a result, the excess orbitals energy spectrum $(\mathrm{EOES})^{3}$ method is employed to reveal the orbital based differences between $\mathrm{E}-\mathrm{Fc}^{+}$and $\mathrm{S}-\mathrm{Fc}^{+}$ conformers. The EOES is also innovatively extended to monitor the behavior of the $\alpha-$ and $\beta$ electrons of a particular $\mathrm{Fc}^{+}$conformer (e.g., eclipsed) at an individual electron level. The EOES for $\alpha$ - and $\beta$-electrons of $E-\mathrm{Fc}^{+}$will be able to provide the electron spin related behavior as an effect of ionization.

Gaussian 09 computational chemistry package ${ }^{31}$ was employed in the present study. The EDA calculations were performed on the basis of ETS scheme ${ }^{32}$ using the Amsterdam Density Functional (ADF) package ${ }^{33}$ with B3LYP/TZ2P+, ${ }^{34}$ a Slater-type basis set.

\section{Results and Discussion}

\section{Performance of quantum mechanical model on Fc}

The inclusion of electron correlation effect in the quantum mechanical model is very important to predict the properties of Fc correctly. The most popular indicators for the accuracy of quantum mechanical models of Fc are the Fe-Cp bond lengths and the IR spectrum. It is 
known that many models have been unable to bring the agreement between the measured and predicted Fc-Cp bond lengths into an acceptable accuracy for Fc. ${ }^{3}$ 10, 11 Moreover, a number of high-level models failed to predict the IR frequencies of Fc. ${ }^{11}$ Those "notoriously challenges" of Fc study along with other measurable properties such as rotational energy barrier and ionization potential etc of the neutral Fc are often employed as a measure for the accuracy of the theoretical models. In this study, in addition to the B3LYP functional, we benchmark a number of recent hybrid functionals such as CAM-B3LYP and meta-hybrid functional M06-2X and ab initio theory such as HF,MP2, MP2(Full) and CCSD(T), HF together with basis sets such as DZP, TZV2P+f and the present $m 6-31 G(d)$. The performance of the models is assessed in reproducing the geometric and other properties of $\mathrm{FC}$ with respect to measurements, which are reported in Table 1.

The models having a high level of electron correlation effect, such as $\operatorname{CCSD}(T), \operatorname{MP} 2$ (full), CAM-B3LYP and B3LYP outperform other models in the same table. For example, the deviations of the energy barrier of Fc are 27.8\% (CCSD(T)), 23.3\%(MP2(full), -33.3\% (CAMB3LYP) and $-35.5 \%$ (B3LYP), respectively. The MP(full)/m6-31G(d) and MP2/m6-31G(d) models, however, introduce the largest errors for Fe-Cp and Fe-C bond distances in the table. It indicates that the MP2 models do not appreciatingly produce the required electron correlation of $\mathrm{Fc}$. The $\mathrm{CCSD}(\mathrm{T}) / \mathrm{TZV} 2 \mathrm{P}+\mathrm{f}^{10}$ model gives more accurate bond lengths of $\mathrm{Fc}$ than the DFT methods except for Fe-C and $\mathrm{C}-\mathrm{H}$ bonds. For example, the discrepancy of the Fe-C bond of $F c$ using the $\operatorname{CCSD}(T) / T Z V 2 P+f^{10}$ model is $0.008 \AA$, while such the discrepancy has been reduced to $0.001 \AA$ if the $B 3 L Y P / m 6-31 G(d)$ model is employed. ${ }^{3}$ Similar trends are found for the results produced by the CAM-B3LYP/m6-31G(d) model. For example, errors for Fe-C, C-C and $\mathrm{C}-\mathrm{H}$ bond lengths of Fc are $0.013,0.018$, and $0.023 \AA$, respectively, when CAM-B3LYP/m6-31G(d) model is employed, which are reduced to $0.001,0.012$, and $0.022 \AA$, respectively, using the $\mathrm{B} 3 \mathrm{LYP} / \mathrm{m6} 6 \mathrm{-31G}(\mathrm{d})$ model. In addition, the results in Table 1 also indicates that the recent M06-2X functional is not suitable to study Fc. The HF and MP2 results do not reproduce the experimental results well, which was also seen from previous studies. ${ }^{10}$, 11 
Table 1: Performance of various models on optimized geometric properties of Fc. ${ }^{*}$

\begin{tabular}{|c|c|c|c|c|c|c|c|c|c|c|}
\hline $\begin{array}{c}\text { Bond } \\
\text { Length }(\AA)\end{array}$ & $\begin{array}{c}\text { B3LYP/ } \\
\text { m6-31G(d) }\end{array}$ & $\begin{array}{c}\mathrm{HF} / \\
\mathrm{m} 6-31 \mathrm{G}(\mathrm{d})\end{array}$ & $\begin{array}{c}\mathrm{HF} / \\
\mathrm{DZP}^{11}\end{array}$ & $\begin{array}{c}\text { MP2/ } \\
\text { m6-31G(d) }\end{array}$ & $\begin{array}{c}\text { MP2/ } \\
\text { TZV2P+f }\end{array}$ & $\begin{array}{l}\text { MP2(Full)/ } \\
\text { m6-31G(d) }\end{array}$ & $\begin{array}{c}\text { M06-2XI } \\
\text { m6-31G(d) }\end{array}$ & $\begin{array}{c}\text { CAM-B3LYP/ } \\
\text { m6-31G(d) }\end{array}$ & $\begin{array}{l}\operatorname{CCSD}(\mathrm{T}) / \\
\mathrm{TZV} 2 \mathrm{P}+\mathrm{f}^{10}\end{array}$ & Exp \\
\hline Fe-Cp & 1.670 & 1.852 & 1.865 & 1.484 & 1.465 & 1.457 & 1.734 & 1.656 & 1.655 & 1.660 \\
\hline$\Delta$ & $(0.010)$ & $(0.192)$ & $(0.205)$ & $(0.176)$ & (0.195) & $(0.203)$ & $(0.074)$ & (0.004) & (0.005) & \\
\hline $\mathrm{Fe}-\mathrm{C}$ & 2.065 & 2.206 & 2.219 & 1.924 & 1.91 & 1.905 & 2.113 & 2.051 & 2.056 & $2.064 \pm 0.0$ \\
\hline$\Delta$ & (0.001) & $(0.142)$ & $(0.155)$ & $(0.140)$ & $(0.154)$ & (0.159) & (0.049) & (0.013) & (0.008) & 03 \\
\hline C-C & 1.428 & 1.41 & 1.413 & 1.441 & 1.441 & 1.443 & 1.420 & 1.422 & 1.433 & $1.440 \pm 0.0$ \\
\hline$\Delta$ & $(0.012)$ & $(0.030)$ & $(0.027)$ & (0.001) & (0.001) & (0.003) & $(0.020)$ & $(0.018)$ & $(0.007)$ & 02 \\
\hline $\mathrm{C}-\mathrm{H}$ & 1.082 & 1.072 & 1.074 & 1.084 & 1.076 & 1.084 & 1.081 & 1.081 & 1.077 & $1.104 \pm 0.0$ \\
\hline$\Delta$ & $(0.022)$ & $(0.027)$ & $(0.030)$ & $(0.020)$ & $(0.028)$ & $(0.020)$ & $(0.023)$ & $(0.023)$ & $(0.027)$ & 06 \\
\hline$\Delta \mathrm{E}^{\mathrm{a}}$ & 0.58 & -0.01 & 0.10 & 2.40 & 4.58 & 1.11 & 0.08 & 0.60 & 1.15 & $0.9 \pm 0.3$ \\
\hline
\end{tabular}

${ }^{*}$ The values within parenthesis indicate the absolute deviation from experimental bond lengths.

${ }^{\text {a }} \Delta \mathrm{E}=\mathrm{E}_{\mathrm{tot}}\left(\mathrm{D}_{5 \mathrm{~d}}\right)-\mathrm{E}_{\mathrm{tot}}\left(\mathrm{D}_{5 \mathrm{~h}}\right)$ in $\mathrm{kcal} \cdot \mathrm{mol}^{-1}$. 
Of the three basis sets DZP, TZV2P+f, and m6-31G(d) studied, the $m 6-31 G(d)$ basis set when combined with the HF and MP2 methods improves those metal centered Fe-C bonds. For example, apparent improvement to the experimental measurements is achieved, when MP2 is combined with the m6-31G(d) basis set over the larger TZV2P+f basis set. ${ }^{[3]}$ In addition to the accuracy, the m6-31G (d) basic set possesses a significantly smaller number of basis primitive functions which will largely reduce the computational costs. For example, the m6-31G(d) basis set contains 194 contracted basis functions for Fc, whereas the DZP basis set consists of 243 primary basis functions and the TZV2P+f basis set has as many as 373 contracted basis functions ${ }^{[3]}$ in this regard. Finally, the $\operatorname{CCSD}(T) / T Z V 2 P+f$ model requires significantly larger computer resources for $\mathrm{Fc}^{\left[{ }^{[3]}\right.}$

The energetics in Table 1 suggest that the B3LYP functional and the more recent CAM-B3LYP functional are more competitive in the prediction of properties of $\mathrm{Fc}$ than other methods in the same table, including ab initio methods such as MP2(full) and $\operatorname{CCSD}(T)$. For example, the energetics calculated by B3LYP and CAM-B3LYP are within the error bars of the energetics obtained from experiment. ${ }^{2}$ However, the B3LYP/m6-31G(d) model produces more accurate vibrational frequencies of Fc than the CAMB3LYP/m6-31G(d) model (see supplementary material, Table S1). For example, the mean absolute error (MAE), the root mean square error (RMSE), and mean absolute percentage error (MAPE) of the B3LYP/m6-31G(d) model are lower than that of the CAM-B3LYP/m6-31G(d) model (see Table S1). The B3LYP/m6-31G(d) model also produces more accurate IR frequencies of Fc with respect to either the measurement of Lippincott and Nelson's pioneer vibrational spectra ${ }^{35}$ or compared with Bodenheimer and Lows's more recent vibrational spectrum of Fc. ${ }^{36}$ In summary, the overall performance of B3LYP method on prediction of the properties of is better than all other available methods so far. ${ }^{10}$

\section{Molecular properties of ferrocenium conformers}

When a ( $\beta-)$ electron leaves the molecule, ferrocene is oxidized, and ferrocenium $\left(\mathrm{Fc}^{+}\right)$is produced. Like the neutral Fc, ferrocenium in its ground electronic state also possesses two conformers with the same symmetry, that is, the eclipsed $(E)$ with the $D_{5 h}$ symmetry and the staggered $(S)$ with the $D_{5 d}$ symmetry. The optimized geometries of $\mathrm{Fc}^{+}$conformers are presented and compared with available theoretical and experimental studies in Table 2. The effect of oxidation on the optimized geometries of the parent neutral Fc conformers is also presented in parenthesis in excess. It is interesting that the geometric changes (i.e. bond lengths and bond angles) in $\mathrm{Fc}^{+}$from $\mathrm{Fc}$ are minimal. For example, the changes in bond lengths are less than $\pm 0.08 \AA$, regardless of the model employed.

Fc and $\mathrm{Fc}^{+}$are very sensitive to the degree of inclusion of electron correlation energy in the quantum mechanical models. For example, the (u)HF method results in a very different (and opposite) trend with shorter Fe-bond distances due to ionization, as shown in Table 2. This suggests that the (u)HF theory is not suitable to study molecules with strong electron correlation effect such as Fc, as previously reported. ${ }^{10-12}$ Methods including electron correlation energy such as MP2 improve the obtained $\mathrm{Fc}^{+}$and Fc properties, but apparently underestimated the metal-related bond distances by around $0.20 \AA$ as 
found in the studies of $\mathrm{Fc}^{10,13}$ and/or $\mathrm{Fc}^{+} .37,38$ As a result, the electronic factors due to the removal of a valence electron play a crucial role in the changes of metal-related bond distances for $\mathrm{Fc}$ and $\mathrm{Fc}^{+} .{ }^{39-41} \mathrm{It}$ also implies that the ionized electron is likely to be an electron belongs to $\mathrm{Fe}$, as indicated by Rosenblum et al. ${ }^{42}$ and Mutoh and Masuda. ${ }^{43}$

Ionization changes other properties of Fc. It reduces the molecule size (i.e., electronic spatial extent $<R^{2}>$ as given in Table 2) slightly from their neutral Fc counterparts, bringing the size of the cation conformer pairs closer in size than their neutral ones. The $\mathrm{S}-\mathrm{Fc}^{+}$is slightly larger than the $\mathrm{E}-\mathrm{Fc}^{+}$by 1.01 a.u., whereas the neutral S-Fc conformer is larger than the E-Fc conformer by 2.94 a.u. The S-Fc ${ }^{+}$shows a more apparent reduction of molecule size than $\mathrm{E}-\mathrm{Fc}^{+}$. For example, the $\left\langle\mathrm{R}^{2}>\right.$ of $\mathrm{S}-\mathrm{Fc}^{+}$reduces by 11.48 a.u., from 1361.78 a.u. in $\mathrm{Fc}^{5}$ to 1350.30 a.u. in $\mathrm{Fc}^{+}$based on the same model; whereas the $<\mathrm{R}^{2}>$ of $\mathrm{E}$ $\mathrm{Fc}^{+}$decreases by 9.55 a.u., from 1358.84 a.u. ${ }^{5}$ to 1349.29 a.u. The opposite trends with respect to the ionization of $\mathrm{Fc}$ in the bond length and molecule size may be due to the following reasons. Firstly, the removal of an outer valence electron reduces the outer electron density so that the electronic spatial extent is smaller in the cation. Secondly, the $\mathrm{Fc}^{+}$is one electron less than the neutral $\mathrm{Fc}$ and the electron removed is likely to be a Fe electron, ${ }^{42,43}$ since the Fe related bond distances such as Fe-C and Fe-Cp of $\mathrm{Fc}^{+}$are expanded. As a result, the Coulomb force responsible for the bonds is less strong than the neutral Fe (see Tables 1 and 2), leading to longer bonds. Finally, it is also noted in Table 2 that the $\Varangle C p-$ $\mathrm{H}$ angles in the $\mathrm{Fc}^{+}$conformers $\left(1.23^{\circ}\right.$ for $\mathrm{E}$ and $1.48^{\circ}$ for $\left.\mathrm{S}\right)$ are almost doubled than they were in neutral Fc conformers $\left(0.66^{\circ}\right.$ for $\mathrm{E}$ and $0.92^{\circ}$ for $\left.\mathrm{S}\right),{ }^{5}$ which justifies the reason behind the decrease of molecule size in $\mathrm{Fc}^{+}$. This situation is similar to two umbrellas connecting on their handles on the central metal Fe, thereby affecting the overall spatial extent.

The small geometric changes of $\mathrm{Fc}^{+}$concentrate on the bonds involved the transition metal Fe. The C$\mathrm{C}$ and $\mathrm{C}-\mathrm{H}$ bond lengths of the cyclopentadienyl $(\mathrm{Cp})$ ring in both $\mathrm{E}$ and $\mathrm{S}-\mathrm{Fc}^{+}$remain almost unchanged with respect to their corresponding Fc conformers. For example, the $\mathrm{C}-\mathrm{C}$ and $\mathrm{C}-\mathrm{H}$ bonds of $\mathrm{Fc}^{+}$are 1.43 $\AA$ and $1.08 \AA$, respectively, for both conformers, which are actually the same as the corresponding bond lengths of $\mathrm{Fc}$ using the same model, in agreement with earlier experimental ${ }^{38}$ and theoretical studies. ${ }^{37}$, 44, 45 However, the oxidation of $\mathrm{Fc}$ (i.e., $\mathrm{Fc}^{+}$) stretches the Fe related bond distances in $\mathrm{Fc}^{+} .37,38,45-47$ Table 2 shows that the Fe-Cp and Fe-C bond distances in both $E\left(D_{5 h}\right)$ and $S\left(D_{5 d}\right)$ of Fc increase slightly by approximately $0.02 \AA$ with respect to their Fc counterparts, which is in agreement with other studies containing sufficient electron correlation, such as Duhović and Diaconescu, ${ }^{44}$ Yang and $\mathrm{Yu},{ }^{37}$ Namazian et al. ${ }^{45}$ and Nakano et al. ${ }^{47}$ etc. The results suggest that the geometrical impact of one electron ionization of $\mathrm{Fc}$ is negligible, but the ionized electron may be related to the central metal. ${ }^{43}$ 
Table 2: Geometric properties of $\mathrm{Fc}^{+}$conformers using different models. *

\begin{tabular}{|c|c|c|c|c|c|c|c|c|c|}
\hline Parameter & $\begin{array}{c}\text { UB3LYP/ } \\
\text { m6-31G(d) }\end{array}$ & $\begin{array}{c}\text { B3LYP/ } \\
6-31+G(d)^{37}\end{array}$ & $\begin{array}{c}\text { B3LYP/ } \\
\text { LANL2TZF }\end{array}$ & $\begin{array}{l}\text { UB3LYP/ } \\
\text { DZVP47 }\end{array}$ & $\begin{array}{c}\text { B97-D/ } \\
6-31+G(d)^{37}\end{array}$ & $\begin{array}{c}\text { UHF/ } \\
m 6-31 G(d)^{a}\end{array}$ & $\begin{array}{c}\text { UMP2/ } \\
\text { m6-31G(d) }\end{array}$ & $\begin{array}{c}M P 2 / \\
6-31+G(d)^{37}\end{array}$ & Expt $^{38}$ \\
\hline \multicolumn{10}{|c|}{ Eclipsed $\left(D_{5 h}\right)$} \\
\hline Fe-Cp $(\AA)$ & $1.69(0.02)$ & $1.70(0.02)$ & $1.70(0.02)$ & $1.693(0.02)$ & $1.71(0.08)$ & $1.80(-0.05)$ & $1.55(0.07)$ & 1.54 & $\begin{array}{c}1.68 \\
(0.02)\end{array}$ \\
\hline $\mathrm{Fe}-\mathrm{C}(\AA)$ & $2.09(0.02)$ & $2.09(0.02)$ & $2.09(0.02)$ & $2.086(0.02)$ & $2.10(0.06)$ & $2.17(-0.04)$ & $1.98(0.06)$ & 1.97 & 2.069 \\
\hline C-C (A) & $1.43(0.0)$ & $1.43(0.0)$ & $1.43(0.0)$ & $1.433(0.0)$ & $1.44(0.0)$ & 1.41 & $1.44(0.00)$ & 1.44 & \\
\hline $\mathrm{C}-\mathrm{H}(\AA)$ & $1.08(0.0)$ & $1.08(0.0)$ & $1.08(0.0)$ & $1.083(0.0)$ & $1.09(0.0)$ & 1.07 & $1.08(0.00)$ & 1.08 & \\
\hline$\Varangle \mathrm{Cp}-\mathrm{H}\left({ }^{\circ}\right)$ & 1.23 & 1.60 & & & 1.80 & 0.29 & 1.20 & 1.60 & \\
\hline$<R^{2}>$ (a.u.) & 1349.29 & & & & & 1438.74 & 1243.46 & & \\
\hline \multicolumn{10}{|c|}{ Staggered $\left(D_{5 d}\right)$} \\
\hline Fe-Cp $(\AA)$ & $1.70(0.02)$ & $1.70(0.02)$ & & & $1.71(0.08)$ & $1.80(-0.05)$ & $1.56(0.06)$ & & $\begin{array}{c}1.701 \\
(0.04) \\
1.71 \\
(0.06)^{d}\end{array}$ \\
\hline Fe-C $(\AA)$ & $2.09(0.02)$ & $2.09(0.02)$ & & & $2.10(0.06)$ & $2.17(-0.04)$ & $1.98(0.05)$ & & $\begin{array}{l}2.046 \\
2.10^{d}\end{array}$ \\
\hline C-C $(\AA)$ & $1.43(0.0)$ & $1.43(0.0)$ & & & $1.43(-0.01)$ & 1.41 & $1.44(0.00)$ & 1.44 & $1.42^{d}$ \\
\hline $\mathrm{C}-\mathrm{H}(\AA)$ & $1.08(0.0)$ & $1.08(0.0)$ & & & $1.09(0.0)$ & 1.07 & $1.08(-0.01)$ & 1.09 & $0.95^{d}$ \\
\hline$\Varangle \mathrm{Cp}-\mathrm{H}\left({ }^{\circ}\right)$ & 1.48 & 1.80 & & & 2.0 & 0.36 & 1.72 & 1.90 & \\
\hline$<\mathrm{R}^{2}>$ (a.u.) & 1350.30 & & & & & 1438.59 & 1246.91 & & \\
\hline$\Delta \mathrm{E}^{\mathrm{c}}$ & 0.36 & 0.54 & & & & 0.03 & 1.03 & & \\
\hline
\end{tabular}

${ }^{*}$ The variations $\left(\Delta=\mathrm{Fc}^{+}-\mathrm{Fc}\right)$ with respect to the corresponding Fc conformer using the same model are given in parenthesis.

a This work (m6-31G(d) for Fe, 6-31G(d) for $\mathrm{C}$ and $\mathrm{H}$ )

${ }^{b}$ Basic Set : LANL2TZF for Fe, 6-31G(d) for $\mathrm{C}$ and $\mathrm{H}\left(\right.$ Ref $\left.^{45}\right)$

${ }^{c} \Delta \mathrm{E}\left(\mathrm{kcal} \cdot \mathrm{mol}^{-1}\right)=\mathrm{E}_{\mathrm{tot}}\left(\mathrm{D}_{5 \mathrm{~d}}\right)-\mathrm{E}_{\text {tot }}\left(\mathrm{D}_{5 \mathrm{~h}}\right)$.

${ }^{\mathrm{d}}$ X-ray crystallography study $\left(\operatorname{Ref}{ }^{46}\right)$. 


\section{Ground electronic states of $\mathrm{Fc}^{+}$conformers}

Like neutral $\mathrm{Fc}$, the $\mathrm{Fc}^{+}$conformer pair shares a common sub-point group symmetry $\left(\mathrm{D}_{5}\right)$. In molecular orbital theory, the inclusion of electron correlation energy could result in different ground electronic state configurations. ${ }^{3}$ The ground electronic state $\left(X^{2} A_{1}\right)$ of $F^{+}$obtained using uB3LYP/m6-31G(d) (and $\mathrm{uHF} / \mathrm{m6}-31 \mathrm{G}(\mathrm{d})$ for reference only) model inherits properties from the $E$ and the $S$ conformer pair of the neutral $F c\left(X^{1} A_{1}\right),{ }^{3}$ upon the removal of a $\beta$-electron. The electronic ground state of open-shell $\mathrm{Fc}^{+}$, which contains $48 \alpha$-electrons and $47 \beta$-electrons, exhibits the same configurations as those of the neutral Fc ( $D_{5 \mathrm{~h}}$ and $D_{5 \mathrm{~d}}$, respectively, see Supplementary Materials). The inheritance from neutral Fc again suggests that the ionized electron is unlikely to belong to either of the $\mathrm{Cp}$ ligands in $\mathrm{Fc}$ or the high symmetry is unable to retain. ${ }^{42,43}$

Figure 1 presents the outer valence orbital diagrams of $\alpha-\mathrm{Fc}^{+}$and $\beta-\mathrm{Fc}^{+}$using the $\mathrm{uB} 3 \mathrm{LYP} / \mathrm{m} 6-31 \mathrm{G}(\mathrm{d})$ model. The outer valence orbital diagram of $\mathrm{Fc}$ is also presented as references. There are a number of interesting features among the outer valence configurations of the neutral Fc (left column), $\alpha-\mathrm{Fc}^{+}$(middle column) and $\beta-\mathrm{Fc}^{+}$(right column) in Figure 1. First, the occupied orbital $8 a_{1}{ }^{\prime}\left(8 a_{1 g}\right)$ serves as the indicator of the ionization of $\mathrm{Fc}$, accompanied by apparent changes in the unoccupied (virtual) orbitals. The $8 \mathrm{a}_{1}{ }^{\prime}$ $\left(8 \mathrm{a}_{1 \mathrm{~g}}\right)$ orbital was the HOMO-1 of Fc (here HOMO presents the highest occupied molecular orbitals) which becomes the SOMO (singly occupied MO) in $\mathrm{Fc}^{+}$. In fact, it moves to the HOMO-3 position in the $\alpha-\mathrm{Fc}^{+}$but becomes the LUMO (lowest unoccupied molecular orbital) in $\beta-\mathrm{Fc}^{+}$, irrespective to the conformers (E or $S$ ). Note that the following discussion will focus on the eclipsed $(E)$ conformer as the $S$ conformer will lead to the same conclusions.

Figure 1: Orbitals levels of Ferrocene and Ferrocenium using uB3LYP/m6-31G(d). The red and blue colors indicate the $\alpha$ and $\beta$ electrons, respectively, for $\mathrm{Fc}^{+}$.

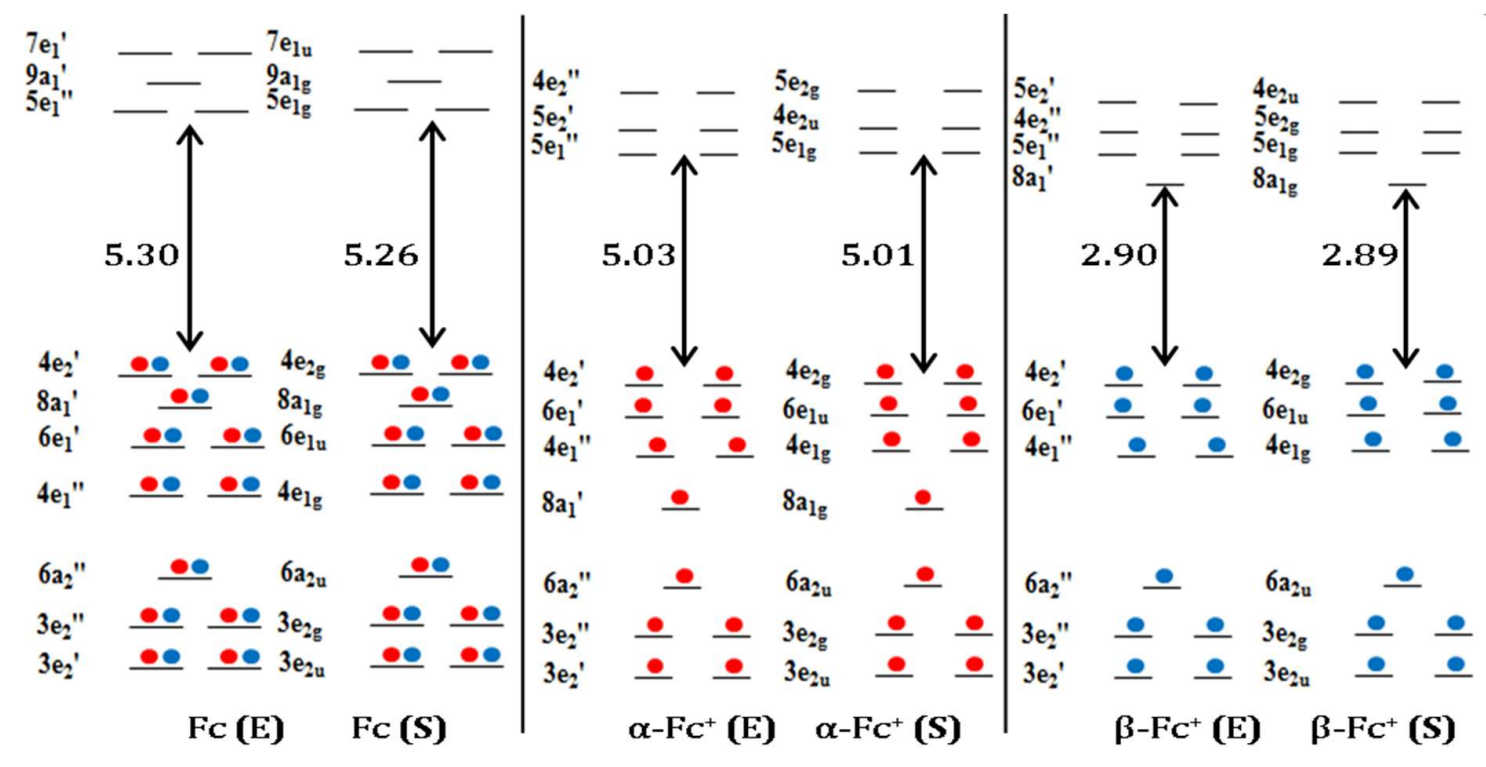


Second, as shown in Figure 1 from orbital energy point of view, the energies of the low lying virtual orbitals of Fc change significantly upon ionization. That is, the virtual orbital energy changes are larger than that found in the occupied outer valence orbitals. For example, the HOMO of E-Fc is doubly degenerate $4 \mathrm{e}_{2}{ }^{\prime},{ }^{3}$ which remains same for E-Fc'. The LUMO, LUMO-1 and LUMO-2 in neutral Fc, $\alpha-\mathrm{Fc}^{+}$ and $\beta-\mathrm{Fc}^{+}$are all different: they are $5 \mathrm{e}_{1}{ }^{\prime \prime}, 9 \mathrm{a}_{1}{ }^{\prime}$ and $7 \mathrm{e}_{1}{ }^{\prime}$, respectively, for $\mathrm{E}-\mathrm{Fc}, 5 \mathrm{e}_{1}{ }^{\prime \prime}, 5 \mathrm{e}_{2}{ }^{\prime}$ and $4 \mathrm{e}_{2}{ }^{\prime \prime}$, respectively for $\alpha-\mathrm{Fc}^{+}$but $8 a_{1}{ }^{\prime}, 5 \mathrm{e}_{1}{ }^{\prime \prime}$, and $4 \mathrm{e}_{2}{ }^{\prime \prime}$, respectively in $\beta-\mathrm{Fc}^{+}$. The configurational changes in low lying virtual orbitals of $\mathrm{Fc}^{+}$are more than orbitals energy shift. Third, the HOMO-LUMO energy gaps of Fc and $\alpha-\mathrm{Fc}^{+}$are not very different, as when orbital $8 a_{1}{ }^{\prime}$ is occupied. The $\mathrm{E}-\mathrm{Fc}$ and $\alpha-\mathrm{Fc}^{+}$have the same HOMOs ( $\left.4 \mathrm{e}_{2}{ }^{\prime}\right)$ and LUMOs ( $\left.5 \mathrm{e}_{1}{ }^{\prime \prime}\right)$ and the energy gap is $5.30 \mathrm{eV}$ for Fc and $5.03 \mathrm{eV}$ for $\alpha-\mathrm{Fc}^{+}$. However, this energy is nearly halved (at $2.90 \mathrm{eV}$ ) in $\beta-\mathrm{Fc}^{+}$after ionization (when orbital $8 \mathrm{a}_{1}{ }^{\prime}$ is unoccupied). For reference purposes, the parallel calculations based on the HF/m6-31G(d) and $\mathrm{uHF} / \mathrm{m6}$-31G(d) models are also performed and given in the Supplementary Materials Figure S1. Perhaps what is in common in the $\mathrm{uHF} / \mathrm{m6}-31 \mathrm{G}(\mathrm{d})$ model is the suggestion that the electron is also ionized from the same $8 \mathrm{a}_{1}{ }^{\prime}$ orbital of $\mathrm{Fc}$, thereby making it as the LUMO of $\beta-\mathrm{Fc}^{+}$.

\section{Orbital based conformational changes in $\mathrm{Fc}^{+}$}

The electronic configuration of $\mathrm{Fc}^{+}$is also examined using the restricted open-shell ROB3LYP/m6$31 \mathrm{G}(\mathrm{d})$ model. It gives the same electron configuration of neutral Fc, except that the HOMO and HOMO1 are exchanged in the ROB3LYP calculation, leading to the singly occupied $8 a_{1}{ }^{\prime}\left(8 a_{1 g}\right)$ orbital the HOMO in $\mathrm{Fc}^{+}$. To explore the orbital based differences between the eclipsed and staggered conformers of $\mathrm{Fc}^{+}$, Figure 2 presents the excess orbital energy spectrum (EOES) of $\mathrm{Fc}^{+}$(black solid squares) using the ROB3LYP/m6-31G(d) model. For comparison, the EOES of neutral Fc (red solid circles) ${ }^{3}$ calculated using the $B 3 L Y P / m 6-31 G(d)$ is also given in the same figure. Note that the orbitals are symmetry correlated, i.e., the orbitals correspond by their symmetry, say $8 a_{1}{ }^{\prime}$, rather than their energy order. As indicated in this figure, ionization of $\mathrm{Fc}$ reduces the orbital based conformer differences in $\mathrm{Fc}^{+}$, that is, the black squares are closer to the x-axis, i.e., $\Delta \varepsilon=0$, than the solid red circles (neutral Fc) with a few exceptions. Therefore, the conformer dependent orbital energy changes in the cation $\left(\mathrm{Fc}^{+}\right)$are less significant than their neutral counterparts Fc, except orbitals MO 21 (4a $\mathrm{a}_{2}$ ) and MO 42-43 (4e $\left.\mathrm{e}_{1}\right)$. This observation is supported by the root mean square (RMS) of the excess energies $\left(\Delta \varepsilon_{i}\right)$, which is reduced from $0.54 \mathrm{kcal} \cdot \mathrm{mol}^{-1}$ in $\mathrm{Fc}$ to $0.40 \mathrm{kcal} \cdot \mathrm{mol}^{-1}$ in $\mathrm{Fc}^{+}$. This suggests that the ionization of an electron from $\mathrm{Fc}$ minimizes the role of the central metal $\mathrm{Fe}$ in $\mathrm{Fc}^{+}$.

The EOES of the occupied orbitals between the $\mathrm{E}$ and $\mathrm{S}$ conformers of $\mathrm{Fc}^{+}$illustrated in Figure 2 shares the same pattern as the EOES of neutral conformers of Fc. The majority of the orbitals prefers E-Fc+ over the $\mathrm{S}-\mathrm{Fc}^{+}$, as the excess orbital energies distribute below the $\mathrm{x}$-axis $(\Delta \varepsilon=0)$. Only less than a quarter of the orbitals (11 out of 48) prefers the S- $\mathrm{Fc}^{+}$conformer; they are MO 20, MO 21, MO 28-29, MO 31, MO 34, MO 39-40, MO 41 and MO 42-43. However, like the neutral Fc conformers, the most significant orbital energy changes between the $\mathrm{Fc}^{+}$conformers originate from the doubly degenerate $\mathrm{Cp}$ dominant 
orbital pairs of $3 e_{2}^{\prime}(\mathrm{MO} 37-38)$ and $3 \mathrm{e}_{2}{ }^{\prime \prime}(\mathrm{MO} 39-40)$, which are outside the $\Delta \varepsilon= \pm 1.0 \mathrm{kcal} \cdot \mathrm{mol}^{-1}$ lines in the figure. These orbitals exhibit contributions from their $C-2 p_{x}$ and $C-2 p_{y}$ atomic orbitals as shown in the same figure. These two orbital pairs are primarily composed of ligand-based atomic orbitals; however, the first orbital pair (MO 37-38) has minimal contributions from Fe (1\%) while the other orbital pair (MO 39-40) has no contributions from metal. The excess energies $(\Delta \varepsilon)$ of these orbital pairs in $\mathrm{Fc}^{+}$are exactly canceled out as the $\Delta \varepsilon$ of MO 37-38 and MO 39-40 are $-1.15 \mathrm{kcal} \cdot \mathrm{mol}^{-1}$ and $1.15 \mathrm{kcal} \cdot \mathrm{mol}^{-1}$, respectively $\left( \pm 1.26 \mathrm{kcal} \cdot \mathrm{mol}^{-1}\right.$ for Fc orbital pair).

The next EOES band of large $\Delta \varepsilon$ changes between the $\mathrm{E}$ and $\mathrm{S}$ conformers of $\mathrm{Fc}^{+}$locates in the orbital energy band $|\Delta \varepsilon|=0.30-1.00 \mathrm{kcal} \cdot \mathrm{mol}^{-1}$. All 12 such orbitals of $\mathrm{Fc}^{+}(14$ orbitals in the $\mathrm{Fc}$ ) are dominated by the center transition metal Fe electrons, most of which are located in either the core-shell or inner valence shell. They are the core orbitals solely composed of Fe 1s, $2 s$ and $2 p$ electrons in MO 1-5 and inner-valence orbitals made up of Fe 3s and 3p electrons in MO 16 and MO 18-19 (with the exception of MO17 (2a $\left.\left.\mathrm{a}_{2} "\right)\right)$, and doubly degenerate valence electrons orbital $4 \mathrm{e}_{2}$ ". All orbitals in this band are below the $\mathrm{x}$-axis $(\Delta \varepsilon=0)$, suggesting that the electrons of the central transition metal Fe prefers the eclipsed orientation of the $\mathrm{Cp}$ pair. The similarities in the EOES patterns between $\mathrm{Fc}$ and $\mathrm{Fc}^{+}$again indicate that the ionization exhibits a minor effect on the Cp ligand. 
Figure 2: The excess orbital energy spectrum (EOES) of the eclipsed and staggered conformers of Fc ${ }^{+}$and of Fc (symmetry corrected).

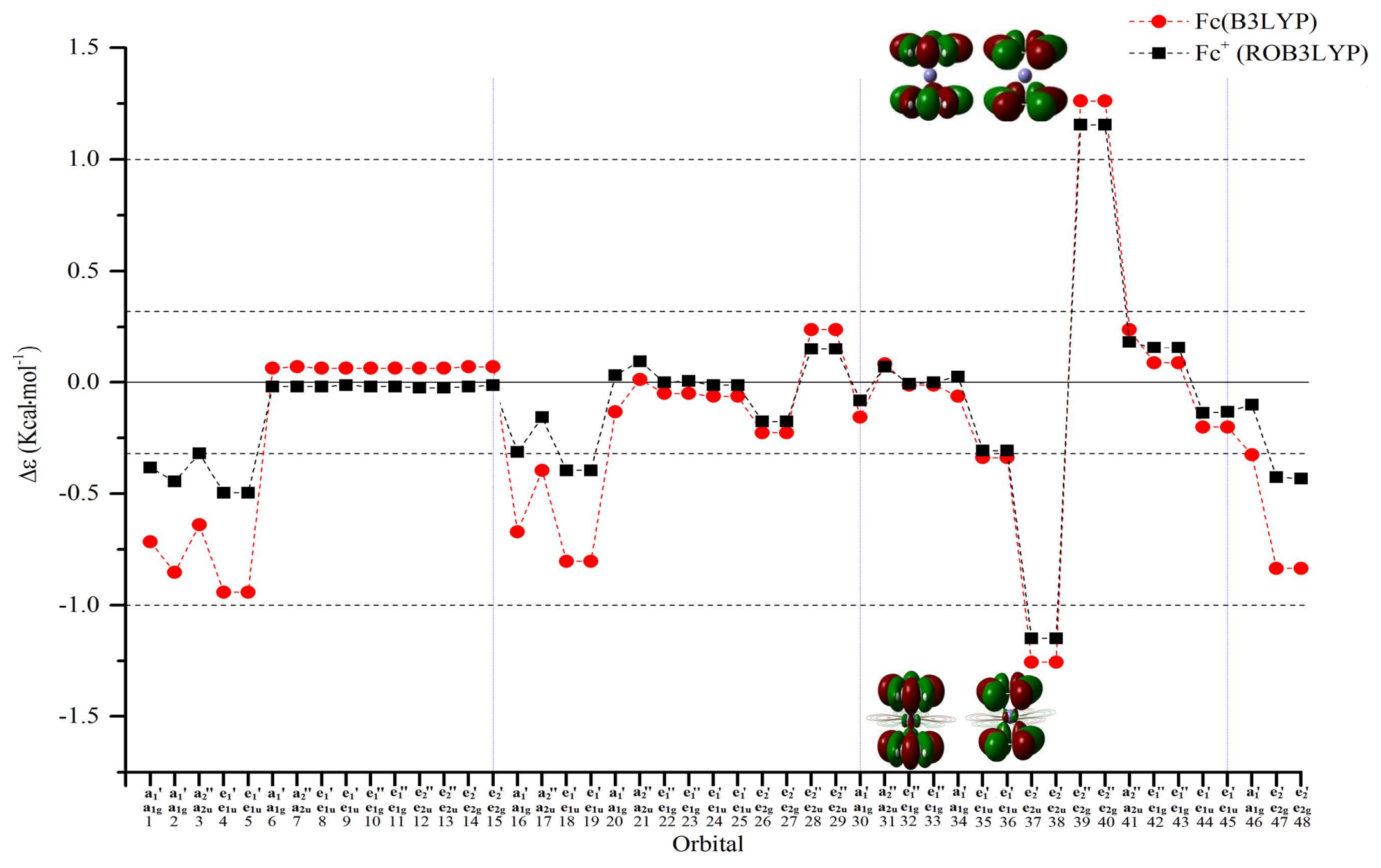




\section{The $\alpha$ - and $\beta$-electrons of Fc ${ }^{+}$}

In molecular orbital theory, the configurations (i.e., the sequence of orbital energies) and orbital symmetries are the measures to reflect the behavior of electrons in a molecule. In addition to revealing the conformer based orbital differences, the present study also extends the excess orbital energy spectrum (EOES) to study the orbital based differences for the $\alpha$-(and $\beta$-) electrons between two $\mathrm{Fc}^{+}$ conformers (i.e., $\mathrm{E}-\mathrm{Fc}^{+}$and $\mathrm{S}-\mathrm{Fc}^{+}$) based on unrestricted model calculations. Figure 3 reports the conformer EOES of $\alpha-\mathrm{Fc}^{+}$(blue diamonds) and $\beta-\mathrm{Fc}^{+}$(pink crosses) as well as neutral $\mathrm{Fc}^{3}$ (red dots for reference). In this figure, two parallel lines at $\Delta \varepsilon= \pm 0.36 \mathrm{kcal} \cdot \mathrm{mol}^{-1}$ represent the total electronic energy difference between E-Fc $\mathrm{F}^{+}$and S-Fc ${ }^{+}$conformers calculated using the uB3LYP/m6-31G(d) model. The excess energies outside of the parallel lines indicate the significant orbital related conformational changes of the particular spin electrons in the cation.

Several features are observed for the spectra illustrated in Figure 3. First, the overall patterns of EOES of $\mathrm{Fc}^{+}$( $\alpha$-electron and/or $\beta$-electrons) are practically similar to the trend of EOES of neutral Fc (red dot line). The EOES in this figure indicates that the nature of the conformer relationship in the $\alpha$ - and $\beta$ electrons of $\mathrm{Fc}^{+}$does not change significantly after ionization. Again, the $\mathrm{Cp}$ ligand dominant orbitals (i.e. MO 37-38 and MO 39-40) give the maximum excess energies; however, they both cancel out each other. Other large conformer dependent orbital energy changes are due to the transition metal Fe dominant orbitals, such as MO 1-5, MO 16, MO 18-19, and MO 47-48, which are identical to those orbitals found for neutral Fc conformers. ${ }^{3}$

Conformer dependent $\alpha$-electrons and $\beta$-electrons of $\mathrm{Fc}^{+}$show similar trends, which is also similar to the neutral Fc conformers. ${ }^{3}$ However, Figure 3 also reveals that in the $\mathrm{Fc}^{+}$cation, the $\alpha$-electrons exhibit more substantial orbital energy changes than the $\beta$-electrons. That is, the blue diamond line is outside of the pink cross curve in Figure 3. This is particularly more obvious for Fe-dominant orbitals, for example, orbitals MO 1-5 (Fe-1s, 2s, 2p), MO 16-19 (Fe-3s,3p), and the doubly degenerate HOMOs (Fe-3d ${ }_{x}^{2}-y^{2}$, $\left.3 d_{x y}\right)$ in addition to the $\mathrm{Cp}$ dominant orbitals MO 37-40. Finally, the orbitals of the E- $\alpha(\beta)-\mathrm{Fc}^{+}$are more negative than the $\mathrm{S}-\alpha(\beta)-\mathrm{Fc}^{+}$, as the majority of the orbitals with large orbital energy changes are below the $\mathrm{x}$-axis. 
Figure 3: The excess orbital energy spectrum (EOES) of eclipsed and staggered conformers of Fc ${ }^{+}(\alpha$ and $\beta)$ and of Fc (symmetry corrected).

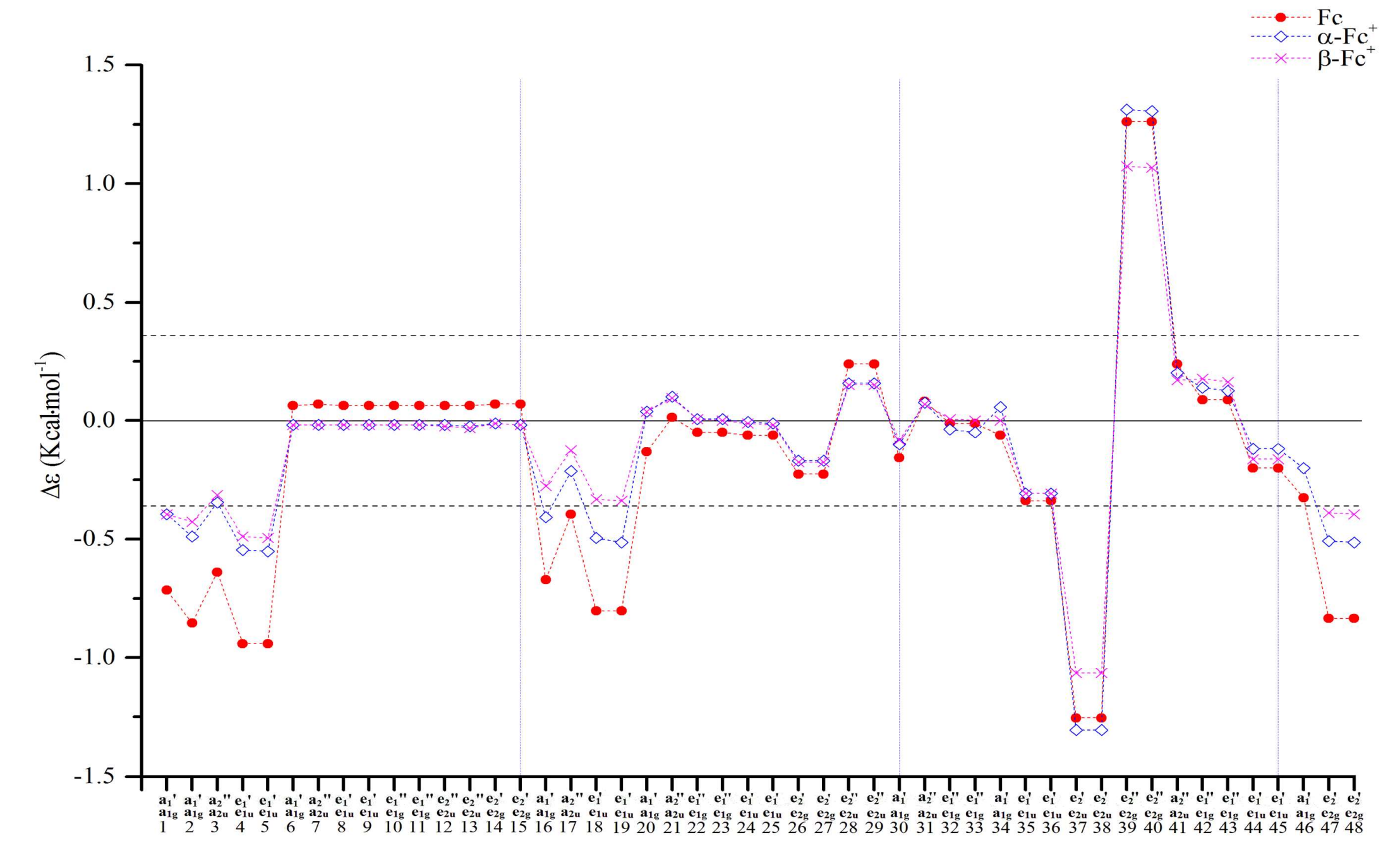




\section{Energy decomposition analysis of $\mathrm{Fc}^{+}$conformers}

Molecular orbital theory decomposes the electrons of a molecule into orbitals based on their energy and distribution. The energy decomposition analysis (EDA), ${ }^{32}$ based on physical characteristics of the energy components is a powerful alternative method to understand the energetics of a compound as it provides insight on the energy cross-sections. ${ }^{20}$ However, the methods of energy decomposition are not unique; only the physically meaningful energy decomposition methods could convey useful insight on the energetics. ${ }^{20}$ That is, the interaction energy $\left(\Delta \mathrm{E}_{\text {Int }}\right)$ can be decomposed into three important quantities that have direct physical origins, ${ }^{33,48,49}$ i.e., $\Delta \mathrm{E}_{\mathrm{Estat}}, \Delta \mathrm{E}_{\text {Pauli, }}$ and $\Delta \mathrm{E}_{\text {Orb. }}$. The EDA has been applied to study neutral $\mathrm{Fc}^{50-56}$ using different fragmentation schemes and more recently, the atomic fragmentation based EDA was employed to study neutral ferrocene conformers. ${ }^{20}$ After the application of EDA to study Fc conformers, ${ }^{20}$ the same approach has been employed to study $\mathrm{Fc}^{+}$in combination with EOES.

Table 3 compares the energetics obtained from the EDA of $\mathrm{Fc}^{+}$and neutral Fc counterparts, using the same extended transition state (ETS) method. ${ }^{32}$ The Amsterdam density functional (ADF) computational chemistry package ${ }^{33}$ is employed for the calculations. It was discovered that the major conformer difference in neutral $\mathrm{Fc}$ is given by the quantum mechanical Pauli repulsive energy $\Delta \mathrm{E}_{\text {Pauli }}$ of 10.61 $\mathrm{kcal} \cdot \mathrm{mol}^{-1},{ }^{20}$ which is nearly canceled by the sum of attractive orbital energy $\Delta \mathrm{E}_{\mathrm{Orb}}$ of $-5.48 \mathrm{kcal} \cdot \mathrm{mol}^{-1}$, and the electrostatic energy $\Delta \mathrm{E}_{\text {Estat }}$ of $-5.25 \mathrm{kcal} \cdot \mathrm{mol}^{-1}$. As a consequence, the eclipsed conformer becomes the energy preferred structure of $\mathrm{Fc}$ by a minimal residue of interaction energy of -0.12 $\mathrm{kcal} \cdot \mathrm{mol}^{-1}$, in agreement with the EOES information.

Table 3: Comparison of the energetics of $\mathrm{Fc}^{+}$conform pair with $\mathrm{Fc}$ conformers $\left(\mathrm{kcal} \cdot \mathrm{mol}^{-1}\right){ }^{1}$

\begin{tabular}{ccccccc}
\hline Energy & \multicolumn{3}{c}{ uB3LYP/TZ2P+ } & \multicolumn{3}{c}{ B3LYP/TZ2P+ } \\
Frag & ${\mathrm{E}-\mathrm{Fc}^{+}}$ & $\mathrm{S}-\mathrm{Fc}^{+}$ & $\Delta \Delta \mathrm{E}_{l}^{2}$ & $\mathrm{E}-\mathrm{Fc}$ & $\mathrm{S}-\mathrm{Fc}$ & $\Delta \Delta \mathrm{E}_{l}^{2}$ \\
\hline$\Delta \mathrm{E}_{\text {Estat }}$ & -2753.54 & -2752.71 & -0.83 & -2792.90 & -2787.65 & -5.25 \\
$\Delta \mathrm{E}_{\text {Pauli }}$ & 8006.50 & 8006.75 & -0.25 & 8097.77 & 8087.16 & 10.61 \\
$\Delta \mathrm{E}_{\text {orb }}$ & -7678.45 & -7679.19 & 0.74 & -7891.75 & -7886.27 & -5.48 \\
$\Delta \mathrm{E}_{\text {Int }}$ & -2425.49 & -2425.15 & -0.34 & -2586.88 & -2586.76 & -0.12 \\
$\Delta \mathrm{E}_{\text {Ster }}$ & 5252.96 & 5254.04 & -1.08 & 5304.87 & 5299.51 & 5.36
\end{tabular}

1 Based on the UB3LYP/m6-31G(d) optimised geometry for $\mathrm{Fc}^{+}$and B3LYP/m6-31G(d) optimised geometry for Fc.

${ }^{2} \Delta \Delta \mathrm{E}_{i}=\Delta \mathrm{E}_{i}(\mathrm{E})-\Delta \mathrm{E}_{i}(\mathrm{~S})$.

As shown in Table 3, the excess decomposed energetics (absolute values) of the $\mathrm{Fc}^{+}$conformers are reduced significantly from the Fc counterparts (refer to Supplementary Materials Figure S2). However, after the cancellation among the three energy components, i.e., $\Delta \mathrm{E}_{\mathrm{Estat}}, \Delta \mathrm{E}_{\text {Pauli, }}$ and $\Delta \mathrm{E}_{\text {Orb, }}$ it results into an even larger (absolute values) interaction energy of $\Delta \mathrm{E}_{\mathrm{lnt}}$ of $-0.34 \mathrm{kcal} \cdot \mathrm{mol}^{-1}$ in $\mathrm{Fc}^{+}$, in compared to the energy of $-0.12 \mathrm{kcal} \cdot \mathrm{mol}^{-1}$ for $\mathrm{Fc}$. The negative interaction energy confirms that the eclipsed conformer is the more stable conformer for both $\mathrm{Fc}_{\mathrm{c}}$ and $\mathrm{Fc}^{+}$, in agreement with results discussed in the previous sections such as EOES. However, it is also noted that the differences in individual energy components of the eclipsed and staggered conformers of $\mathrm{Fc}$ are more apparent than $\mathrm{Fc}^{+}$even though the latter system 
$\left(\mathrm{Fc}^{+}\right)$gives larger interaction energy $\Delta \mathrm{E}_{\text {Int }}$ difference than $\mathrm{Fc}$. That is, the $\Delta \mathrm{E}_{\mathrm{Estat}}, \Delta \mathrm{E}_{\text {Pauli, }}$ and $\Delta \mathrm{E}_{\mathrm{Orb}}$ of $\mathrm{Fc}^{+}$ conformers are significantly smaller as the absolute energies of each energy component $\left|\Delta \Delta \mathrm{E}_{i}\right|$ are less than $1 \mathrm{kcal} \cdot \mathrm{mol}^{-1}$, whereas these energy components are all larger than $5 \mathrm{kcal} \cdot \mathrm{mol}^{-1}$ in $\mathrm{Fc}$.

Ionization of an electron from Fc significantly changes the electron structure of Fc. Table 3 indicates that the order of excess energy contribution in the $\mathrm{Fc}^{+}$conformers is $\left|\Delta \Delta \mathrm{E}_{\text {Estat }}\right|>\left|\Delta \Delta \mathrm{E}_{\text {Pauli }}\right|>\left|\Delta \Delta \mathrm{E}_{\text {Orb }}\right|$. The electrostatic energy becomes the leading excess energy in $\mathrm{Fc}^{+}$but stays attractive. However, the excess Pauli and orbital energies of $\mathrm{Fc}^{+}$switch signs from Fc. The excess electrostatic energy $\left(\Delta \Delta \mathrm{E}_{\mathrm{Estat}}\right)$ increases up to $45.6 \%$ (i.e. $\left.-0.83 \mathrm{kcal} \cdot \mathrm{mol}^{-1}\right)$ in $\mathrm{Fc}^{+}$from $24.6 \%\left(-5.25 \mathrm{kcal} \cdot \mathrm{mol}^{-1}\right)$ in $\mathrm{Fc}$. On the other hand, the relative difference in the quantum mechanical Pauli energy $\left(\Delta \mathrm{E}_{\text {Pauli }}\right)$ of $\mathrm{Fc}^{+}$is $-0.25 \mathrm{kcal} \cdot \mathrm{mol}^{-1}$, which is reduced to $13.7 \%$ in $\mathrm{Fc}^{+}$from $49.7 \%\left(10.61 \mathrm{kcal} \cdot \mathrm{mol}^{-1}\right)$ in $\mathrm{Fc}$. Moreover, the excess orbital energy $\Delta \mathrm{E}_{\mathrm{Orb}}$ of $\mathrm{Fc}^{+}$becomes repulsive, which is given by $0.74 \mathrm{kcal} \cdot \mathrm{mol}^{-1}$ in $\mathrm{Fc}^{+}$(about $40.7 \%$ ) but switching sign from attractive $-5.48 \mathrm{kcal} \cdot \mathrm{mol}^{-1}(25.7 \%)$ in $\mathrm{Fc}^{20}$ As a result, it is the electrostatic energy $\left(\Delta \mathrm{E}_{\mathrm{Estat}}=-0.83\right.$ $\left.\mathrm{kcal} \cdot \mathrm{mol}^{-1}\right)$ which dominates the interaction energy of the $\mathrm{FC}^{+}(45.6 \%)$ and prefers the eclipsed conformer. In summary, the removal of an electron from ferrocene significantly reduces (absolute value) the excess Pauli and electrostatic energies, but increases the excess orbital energy from attractive to repulsive in $\mathrm{Fc}^{+}$. The fact that ferrocenium prefers the eclipsed $\mathrm{Fc}^{+}$is due to different reasons to $\mathrm{Fc}$.

\section{Conclusions}

Ferrocenium conformer $\left(\mathrm{Fc}^{+}\right)$inherits the geometric and other electronic properties from the neutral ferrocene counterparts. It $\left(\mathrm{Fc}^{+}\right)$retains the same high symmetry of neutral $\mathrm{Fc}$ and prefers the eclipsed $\left(D_{5 h}\right)$ conformer over the staggered $\left(D_{5 d}\right)$ conformer by an energy of $0.36 \mathrm{kcal} \cdot \mathrm{mol}^{-1}$. The geometries of $\mathrm{Fc}^{+}$show only a small perturbation from the neutral counterpart with small changes in the transition metal related bond distances and angles, indicating that the ionization of Fc does not affect the Fc structure significantly. The present excess orbital energy spectra (EOES) indicate that the conformer dependent configurational changes between $\mathrm{Fc}^{+}$conformers are also similar to the neutral Fc counterparts but with smaller magnitudes. The present study further indicates that the $\alpha$-electrons show a more significant conformer dependent changes than the $\beta$-electrons in $\mathrm{Fc}^{+}$(note that a $\beta$-electron is removed) as the root mean squares (RMS) of the $\alpha$-EOES and $\beta$-EOES of $\mathrm{Fc}^{+}$are $0.45 \mathrm{kcal} \cdot \mathrm{mol}^{-1}$ and $0.37 \mathrm{kcal} \cdot \mathrm{mol}^{-1}$, respectively. The energy decomposition analysis (EDA) further reveals that the eclipsed rotamer retains as the more energetically preferred structure of $\mathrm{Fc}_{\mathrm{c}}$ and $\mathrm{Fc}^{+}$; however, the underlying justification of such higher stability is different between the neutral and ionized Fc. In particular, the electrostatic energy $\Delta \mathrm{E}_{\mathrm{Estat}}$ gives the key conformer preference in $\mathrm{Fc}^{+}$, whereas the quantum mechanical Pauli energy $\Delta \mathrm{E}_{\text {Pauli }}$ is the dominant energy component in Fc. 


\section{Acknowledgments}

SI acknowledges Swinburne University Postgraduate Research Award (SUPRA). FW acknowledge Swinburne University of Tehcnology for financial support of her six months academic sabbatical leave in 2017. Finally, Swinburne University Supercomputing Facilities must also be acknowledged.

\section{References}

1. J. I. Seeman and S. Cantrill, Nature Chemistry, 2016, 8, 193-200.

2. A. Haaland and J. E. Nilsson, Acta Chemica Scandinavica, 1968, 22, 2653-2670.

3. S. Islam and F. Wang, RSC Advances, 2015, 5, 11933-11941.

4. F. A. Cotton, G. Wilkinson, C. A. Murillo and M. Bochmann, Advanced Inorganic Chemistry, John Wiley \& Sons, New York, 5th edn. edn., 1988.

5. N. Mohammadi, A. Ganesan, C. T. Chantler and F. Wang, Journal of Organometallic Chemistry, 2012, 713, 51-59.

6. Y. Yamaguchi, W. Ding, C. T. Sanderson, M. L. Borden, M. J. Morgan and C. Kutal, Coordination Chemistry Reviews, 2007, 251, 515-524.

7. M. T. Islam, S. P. Best, J. D. Bourke, L. J. Tantau, C. Q. Tran, F. Wang and C. T. Chantler, The Journal of Physical Chemistry C, 2016, 120, 9399-9418.

8. S. P. Best, F. Wang, M. T. Islam, S. Islam, D. Appadoo, R. M. Trevorah and C. T. Chantler, Chemistry - A European Journal, 2016, 22, 18019-18026.

9. J. D. Bourke, M. T. Islam, S. P. Best, C. Q. Tran, F. Wang and C. T. Chantler, The Journal of Physical Chemistry Letters, 2016, 7, 2792-2796.

10. S. Coriani, A. Haaland, T. Helgaker and P. Jørgensen, ChemPhysChem, 2006, 7, 245-249.

11. Z.-F. Xu, Y. Xie, W.-L. Feng and H. F. Schaefer, The Journal of Physical Chemistry A, 2003, 107, 2716-2729.

12. H. P. Lüthi, J. H. Ammeter, J. Almlöf and K. Faegri, The Journal of Chemical Physics, 1982, 77, 2002-2009.

13. W. Klopper and H. P. Lüthi, Chemical Physics Letters, 1996, 262, 546-552.

14. A. Sengupta, R. O. Ramabhadran and K. Raghavachari, Journal of Computational Chemistry, 2016, 37, 286-295. 
15. Q. M. Phung, S. Vancoillie and K. Pierloot, Journal of Chemical Theory and Computation, 2012, 8, 883-892.

16. A. Dreuw and M. Head-Gordon, Journal of the American Chemical Society, 2004, 126, 4007-4016.

17. K. Kornobis, N. Kumar, B. M. Wong, P. Lodowski, M. Jaworska, T. Andruniów, K. Ruud and P. M. Kozlowski, The Journal of Physical Chemistry A, 2011, 115, 1280-1292.

18. K. Kornobis, N. Kumar, P. Lodowski, M. Jaworska, P. Piecuch, J. J. Lutz, B. M. Wong and P. M. Kozlowski, Journal of Computational Chemistry, 2013, 34, 987-1004.

19. S. Chiodo, N. Russo and E. Sicilia, Journal of Computational Chemistry, 2005, 26, 175-184.

20. F. Wang, S. Islam and V. Vasilyev, Materials, 2015, 8, 7723-7737.

21. L. Kun, N. Chuan-Gang, S. Le-Lei, M. Yu-Run and D. Jing-Kang, Acta Physica Sinica, 2011, 60, 023402.

22. U. Salzner, Journal of Chemical Theory and Computation, 2013, 9, 4064-4073.

23. S. Scuppa, L. Orian, D. Dini, S. Santi and M. Meneghetti, The Journal of Physical Chemistry A, 2009, 113, 9286-9294.

24. E. Fromager, S. Knecht and H. J. A. Jensen, The Journal of Chemical Physics, 2013, 138, 084101.

25. A. V. Mitin, J. Baker and P. Pulay, The Journal of Chemical Physics, 2003, 118, 7775-7782.

26. M. T. Islam, S. P. Best, J. D. Bourke, L. J. Tantau, C. Q. Tran, F. Wang and C. T. Chantler, The Journal of Physical Chemistry C, 2016, 120, 9399-9418.

27. Y. Zhao and D. G. Truhlar, Theoretical Chemistry Accounts, 2008, 120, 215-241.

28. F. Wang, The Journal of Physical Chemistry A, 2003, 107, 10199-10207.

29. F. Wang, P. Duffy and D. P. Chong, in Nanoscale Interactions and Their Applications: Essays in Honour of lan McCarthy, eds. F. Wang and M. J. Brunger, Transworld Research Network, Kerala, 2007, pp. 169-182.

30. J. Martin, J. Baker and P. Pulay, Journal of Computational Chemistry, 2009, 30, 881-883.

31. M. J. Frisch, G. W. Trucks, H. B. Schlegel, G. E. Scuseria, M. A. Robb, J. R. Cheeseman, G. Scalmani, V. Barone, B. Mennucci, G. A. Petersson, H. Nakatsuji, M. Caricato, X. Li, H. P. Hratchian, A. F. Izmaylov, J. Bloino, G. Zheng, J. L. Sonnenberg, M. Hada, M. Ehara, K. Toyota, R. Fukuda, J. Hasegawa, M. Ishida, T. Nakajima, Y. Honda, O. Kitao, H. Nakai, T. Vreven, J. A. Montgomery Jr., J. E. Peralta, F. Ogliaro, M. J. Bearpark, J. Heyd, E. N. Brothers, K. N. Kudin, V. N. Staroverov, R. Kobayashi, J. Normand, K. Raghavachari, A. P. Rendell, J. C. Burant, S. S. Iyengar, J. Tomasi, M. Cossi, N. Rega, 
N. J. Millam, M. Klene, J. E. Knox, J. B. Cross, V. Bakken, C. Adamo, J. Jaramillo, R. Gomperts, R. E. Stratmann, O. Yazyev, A. J. Austin, R. Cammi, C. Pomelli, J. W. Ochterski, R. L. Martin, K. Morokuma, V. G. Zakrzewski, G. A. Voth, P. Salvador, J. J. Dannenberg, S. Dapprich, A. D. Daniels, Ö. Farkas, J. B. Foresman, J. V. Ortiz, J. Cioslowski and D. J. Fox, Gaussian 09, Revision E.01, Gaussian, Inc.: Wallingford, CT, 2013.

32. T. Ziegler and A. Rauk, Theoret. Chim. Acta, 1977, 46, 1-10.

33. E. J. Baerends, T. Ziegler, A. J. Atkins, J. Autschbach, D. Bashford, A. Bérces, F. M. Bickelhaupt, C. Bo, P. M. Boerrigter, L. Cavallo, D. P. Chong, D. V. Chulhai, L. Deng, R. M. Dickson, J. M. Dieterich, D. E. Ellis, M. v. Faassen, T. H. F. L. Fan, C. F. Guerra, M. Franchini, A. Ghysels, A. Giammona, S. J. A. v. Gisbergen, A. W. Götz, J. A. Groeneveld, O. V. Gritsenko, M. Grüning, S. Gusarov, F. E. Harris, P. v. d. Hoek, C. R. Jacob, H. Jacobsen, L. Jensen, J. W. Kaminski, G. v. Kessel, F. Kootstra, A. Kovalenko, M. V. Krykunov, E. v. Lenthe, D. A. McCormack, A. Michalak, M. Mitoraj, S. M. Morton, J. Neugebauer, V. P. Nicu, L. Noodleman, V. P. Osinga, S. Patchkovskii, M. Pavanello, C. A. Peeples, P. H. T. Philipsen, D. Post, C. C. Pye, W. Ravenek, J. I. Rodríguez, P. Ros, R. Rüger, P. R. T. Schipper, H. v. Schoot, G. Schreckenbach, J. S. Seldenthuis, M. Seth, J. G. Snijders, M. Solà, M. Swart, D. Swerhone, G. t. Velde, P. Vernooijs, L. Versluis, L. Visscher, O. Visser, F. Wang, T. A. Wesolowski, E. M. v. Wezenbeek, G. Wiesenekker, S. K. Wolff, T. K. Woo and A. L. Yakovlev, ADF2014, SCM, Theoretical Chemistry; Vrije Universiteit: Amsterdam, 2014.

34. D. P. Chong, E. Van Lenthe, S. Van Gisbergen and E. J. Baerends, Journal of Computational Chemistry, 2004, 25, 1030-1036.

35. E. R. Lippincott and R. D. Nelson, Spectrochimica Acta, 1958, 10, 307-329.

36. J. S. Bodenheimer and W. Low, Spectrochimica Acta Part A: Molecular Spectroscopy, 1973, 29, 1733-1743.

37. Y. Yang and L. Yu, Physical Chemistry Chemical Physics, 2013, 15, 2669-2683.

38. R. Martinez and A. Tiripicchio, Acta Crystallographica Section C, 1990, 46, 202-205.

39. M. R. Churchill, A. G. Landers and A. L. Rheingold, Inorganic Chemistry, 1981, 20, 849-853.

40. J. W. Lauher and R. Hoffmann, Journal of the American Chemical Society, 1976, 98, 1729-1742.

41. E. M. Schustorovich and M. E. Dyatkina, Doklady Akademii nauk SSSR, 1959, 128, 1234.

42. M. Rosenblum, J. O. Santer and W. G. Howells, Journal of the American Chemical Society, 1963, $85,1450-1458$.

43. H. Mutoh and S. Masuda, Journal of the Chemical Society, Dalton Transactions, 2002, DOI: 10.1039/B111486G, 1875-1881. 
44. S. Duhović and P. L. Diaconescu, Polyhedron, 2013, 52, 377-388.

45. M. Namazian, C. Y. Lin and M. L. Coote, Journal of Chemical Theory and Computation, 2010, 6, 2721-2725.

46. S. Scholz, M. Scheibitz, F. Schödel, M. Bolte, M. Wagner and H.-W. Lerner, Inorganica Chimica Acta, 2007, 360, 3323-3329.

47. H. Nakano, J. Noguchi, T. Mochida and H. Sato, The Journal of Physical Chemistry A, 2015, 119, 5181-5188.

48. G. Frenking and N. Fröhlich, Chemical Reviews, 2000, 100, 717-774.

49. L. P. Wolters and F. M. Bickelhaupt, Wiley Interdisciplinary Reviews: Computational Molecular Science, 2015, 5, 324-343.

50. M. J. Mayor-López and J. Weber, Chemical Physics Letters, 1997, 281, 226-232.

51. J. Frunzke, M. Lein and G. Frenking, Organometallics, 2002, 21, 3351-3359.

52. V. M. Rayón and G. Frenking, Organometallics, 2003, 22, 3304-3308.

53. M. Lein, J. Frunzke, A. Timoshkin and G. Frenking, Chemistry - A European Journal, 2001, 7, 41554163.

54. Z. Gomez-Sandoval, E. Peña, C. F. Guerra, F. M. Bickelhaupt, M. A. Mendez-Rojas and G. Merino, Inorganic Chemistry, 2009, 48, 2714-2716.

55. M. Swart, Inorganica Chimica Acta, 2007, 360, 179-189.

56. G. Zhang, H. Zhang, M. Sun, Y. Liu, X. Pang, X. Yu, B. Liu and Z. Li, Journal of Computational Chemistry, 2007, 28, 2260-2274. 